Artigo Original

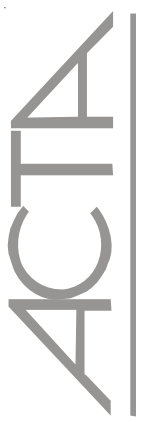

\title{
O suporte durante o processo de parturição: a visão do acompanhante
}

\author{
Support during the labor and delivery processes: viewpoint of companions of women giving birth \\ El apyo durante el proceso del parto: la óptica del acompañante

\section{Ana Márcia Spanó Nakano', Luciene Amorin Silva², Ana Carolina Sartorato Beleza ${ }^{3}$, Juliana Stefanello ${ }^{4}$, Flávia Azevedo Gomes ${ }^{5}$}

\section{RESUMO}

Objetivo: Objetivou-se, neste estudo, compreender o significado de ser acompanhante de uma mulher em trabalho de parto e parto. Os sujeitos do estudo foram 12 acompanhantes de parturientes assistidas em uma maternidade. Métodos: A abordagem metodológica utilizada foi a qualitativa e a análise dos dados foi fundamentada na técnica de análise de conteúdo. Resultado: Os significados observados para a participação do acompanhante foram: "dar força", "ficar junto/ao lado" e "observar tudo". No espaço hospitalar de domínio médico, o acompanhante relatou que "quem faz é o médico"; algumas vezes se perceberam "sem coragem" e "sem atitude". Conclusão:Diante de tais resultados, verificou-se que é preciso dar voz aos agentes envolvidos diretamente no processo de parturição, que muitas vezes sentem-se intimidados pelos profissionais de saúde, desencorajados de participar, ou assumindo um papel fiscalizador na tentativa de obter uma assistência segura para a parturiente.

Descritores: Acompanhantes de paciente; Trabalho de parto; Parto; Saúde da mulher

\begin{abstract}
Purpose: The aim of this study was to understand what it means to be a companion of women during the labor and delivery processes. Methods: The sample consisted of 12 companions of women giving birth in a Brazilian maternity. A qualitative design was used to conduct the study. Data from interviews were examined with content analysis. Results: The findings suggest that being a companion means, "to give support," "to be together/at the side" and "to observe everything." In the domain, observing medical care in a hospital setting, companions stated, "the physician does all the work"; and sometimes companions regarded themselves "without courage" and "without attitude." Conclusion: It is necessary to give a voice to companions during the labor and delivery processes. Companions very often feel intimidated by health professionals, discouraged, or just assuming an observer role when attempting to support women giving birth.
\end{abstract}

keywords: Patient Escort Service; Labor, Obstetric; Parturition; Women's health

\section{RESUMEN}

Objetivo: En este estudio se tuvo como objetivo, comprender el significado de ser acompañante de una mujer en trabajo de parto y parto. Los sujetos del estudio fueron 12 acompañantes de parturientas asistidas en una maternidad. Métodos: El abordaje metodológico utilizado fue el cualitativo y el análisis de los datos se fundamentó en la técnica del análisis de contenido. Resultados:Los significados observados para la participación del acompañante fueron: "dar fuerza", "quedarse junto/al lado" y "observar todo". En el espacio hospitalario de dominio médico, el acompañante relató que "quien hace es el médico"; algunas veces se percibieron "sin coraje” y "sin actitud”. Conclusión: Frente a tales resultados, se verificó que es preciso dar voz a los agentes involucrados directamente en el proceso del parto, que muchas veces se sienten intimidados por los profesionales de salud, cohibidos de participar, o asumiendo un papel fiscalizador en el intento de obtener una asistencia segura para la parturienta.

Descriptores: Acompañantes del paciente; Trabajo de parto; Parto; Salud de la mujer

* Trabalho realizado na Maternidade do Complexo Aeroporto (MATER), entidade filantrópica mantida pela Fundação Maternidade Sinhá Junqueira, Ribeirão Preto, (SP), Brasil.

1 Professora Associada do Departamento de Enfermagem Materno-Infantil e Saúde Pública da Escola de Enfermagem da Universidade de São Paulo - USP

- Ribeirão Preto (SP), Brasil.

2 Enfermeira Trainee do Hospital e Maternidade São Luiz. - São Paulo ( SP), Brasil; Especailizanda em Enfermagem Obstétrica da Universidade Federal de São Paulo-UNIFESP - São Paulo (SP), Brasil

3 Mestre em Enfermagem em Saúde Pública; Docente da Univerisdade Paulista - UNIP e Faculdades Integradas - Fafibe - São Paulo (SP), Brasil.

4 Professora Assistente do Departamento de Enfermagem Materno-Infantil e Saúde Pública da Escola de Enfermagem de Ribeirão Preto da Universidade de São Paulo - USP - Ribeirão Preto (SP), Brasil

5 Professora Doutora do Departamento de Enfermagem Materno-Infantil e Saúde Pública da Escola de Enfermagem da Universidade de São Paulo - USP Ribeirão Preto (SP), Brasil. 


\section{INTRODUÇÃO}

Com a institucionalização do parto, as mulheres deixaram de parir em seus lares, no ambiente familiar, vivendo a ruptura dos hábitos de solidariedade feminina e do espaço da vida cotidiana. As práticas instituídas baseadas em normas e rotinas tornaram as mulheres passivas e impossibilitaram a presença de pessoas de seu convívio social para apoiá-las ${ }^{(1)}$. A institucionalização do parto foi determinante para afastar a família do processo de nascimento e parto, atendendo às necessidades dos profissionais de saúde em detrimento das necessidades das parturientes ${ }^{(2)}$.

Consideramos que a tecnologia e a humanização não são excludentes; ambas são necessárias a um bom cuidado à saúde. Com a institucionalização do processo reprodutivo, a mulher adquiriu o acesso à tecnologia e ao atendimento por um profissional qualificado, embora tal realidade não seja extensiva a todas as mulheres brasileiras.

A Organização Mundial de Saúde recomenda práticas reconhecidamente benéficas para assistência ao parto de baixo risco. O Projeto Maternidade Segura, criado em 1995, preconiza um modelo de atenção ao parto e ao nascimento menos intervencionista e mais humanizado ${ }^{(3-4)}$. Dentre os princípios para assistência humanizada, é incluída a presença de um acompanhante durante o trabalho de parto que pode ser o companheiro ou alguém da família. O Ministério da Saúde estabelece um protocolo assistencial, indicando a necessidade de que a parturiente disponha de um acompanhante de sua escolha ${ }^{(5)}$. Esse acompanhamento visa a prestação de apoio e encorajamento constantes à mulher, o que proporciona maior segurança e conforto durante o trabalho de parto e parto.

Estudos têm comprovado que o apoio contínuo durante o trabalho de parto beneficia as parturientes e contribui para redução das taxas de cesariana, da duração do trabalho de parto, incentiva o aleitamento e a mulher desenvolve uma percepção positiva sobre esses eventos ${ }^{(6-8)}$.

Apesar das evidências científicas sobre os benefícios do acompanhante para a melhoria do bem-estar da mãe e recém-nascido, a incorporação desta prática pelos profissionais e instituições ainda não se constitui uma realidade em muitos serviços. A implementação desta prática demanda revisão de conceitos de assistência. Muitos profissionais possuem crenças e valores arraigados que rejeitam a idéia da presença do acompanhante no parto ${ }^{(9-11)}$.

Esforços conjuntos da Rede de Humanização do Nascimento, Rede Nacional Feminista de Saúde e da Associação Brasileira de Obstetrizes e Enfermeiras Obstétricas $^{(12)}$, contribuíram para que a Lei n.11.108, de 07 de abril de 2005, fosse aprovada e sancionada. Esta lei obriga os serviços de saúde do Sistema Único de Saúde a permitirem a presença de um acompanhante escolhido pela parturiente durante o período de trabalho de parto, parto e pós-parto imediato ${ }^{(13)}$.

Esta lei não necessariamente garante a efetiva participação do acompanhante como pessoa que ofereça conselhos, medidas de conforto físico e emocional à parturiente. A presença de um acompanhante, mesmo que escolhido pela parturiente, por si só não é considerada sinônimo de suporte, para tanto, é preciso dar condições para a realização dessa atividade ${ }^{(1)}$.

Atuando em uma Maternidade no interior do Estado de São Paulo, pioneira em oferecer estas ações, temos refletido sobre a efetividade da humanização no trabalho de parto e parto. A observação não sistematizada sobre a atuação do acompanhante nos mostra que este se apresenta como um figurante, não exercendo a participação plena enquanto sujeito do processo de suporte à parturiente. Nesse sentido, acreditamos ser necessário, primeiramente, dar voz aos acompanhantes acerca de sua participação no processo de parturição. Para tal partimos das seguintes questões norteadoras: Como os acompanhantes percebem sua presença no contexto institucionalizado de assistência ao parto? Como identificam sua participação junto à parturiente? Que sentimentos, idéias e valores tais vivencias lhes despertaram.

Pressupomos, que os significados atribuídos pelos acompanhantes sobre sua participação junto à parturiente evidenciem dissonâncias com o modelo preconizado de assistência humanizada, no qual o suporte esperado é de proporcionar apoio emocional e conforto físico. No contexto institucionalizado do cuidado, o espaço de atuação do acompanhante é ainda restrito, em razão das relações hierárquicas entre profissional de saúde e usuário, do modelo técnico e instrumental do cuidado, do desconhecimento e do despreparo do acompanhante para exercer um papel ativo no suporte a mulher no trabalho de parto.

Diante do exposto, o objetivo deste estudo foi compreender o significado de ser acompanhante da mulher durante processo de parturição, pressupondo que tal estudo traria subsídios na elaboração de estratégias de preparação dos acompanhantes para que possam exercer um efetivo suporte à parturiente, possibilitandolhes viver experiências positivas em relação a este papel.

\section{MÉTODOS}

Tratou-se de um estudo de abordagem qualitativa, desenvolvido na Maternidade do Complexo Aeroporto (MATER), entidade filantrópica mantida pela Fundação Maternidade Sinhá Junqueira, situada no município de Ribeirão Preto, São Paulo. Esta maternidade está inserida 
no sistema de referência pela Rede Básica de Saúde para resolução de partos de baixo risco em mais de 25 cidades da região de Ribeirão Preto, realizando em torno de 300 partos por mês.

Esta instituição é destinada exclusivamente ao atendimento de pacientes oriundas do Sistema Único de Saúde. O corpo clínico da MATER é formado por médicos e pós-graduandos de residência médica nas áreas de obstetrícia e neonatologia. A equipe de enfermagem é formada por enfermeiras obstétricas, auxiliares de enfermagem e enfermeiras residentes em Enfermagem Obstétrica e Neonatal. Do total de partos assistidos pela equipe, $10 \%$ são realizados por enfermeiras obstétricas.

Os sujeitos do estudo incluem acompanhantes de parturientes assistidas nessa instituição. A escolha da amostra fundamentou-se na concepção de que a amostra ideal é aquela capaz de privilegiar os sujeitos sociais que possuem os atributos que se pretende estudar, de forma que atenda aos objetivos da pesquisa. Sendo assim, foram considerados os acompanhantes que estiveram presentes integralmente ou durante parte do processo de parturição. O tamanho da amostra foi definido com base no critério de saturação ou exaustão dos dados contidos nas entrevistas $^{(14)}$.

\section{Coleta de Dados}

Foram seguidas as normas para pesquisa envolvendo seres humanos, estabelecidas pela Resolução n. ${ }^{\circ}$ 196/96 do Conselho Nacional de Saúde. O projeto foi submetido ao Comitê de Ética em Pesquisa da EERP-USP. Os 12 sujeitos que cumpriam os critérios de inclusão foram convidados a participar da pesquisa e mediante aceitação, foi solicitado que assinassem o Termo de Consentimento Livre e Esclarecido. Com o objetivo de garantir o anonimato dos sujeitos pesquisados, nos fragmentos das entrevistas, foram utilizados códigos de identificação.

Os dados foram coletados através de entrevistas individuais, gravadas, para as quais se adotou a técnica de depoimento pessoal. Tal técnica permite estimular as pessoas a falarem como pensam e fazem as coisas acerca do tema em questão, e permite ao pesquisador focalizar e aprofundar mais os aspectos relativos aos objetivos do estudo, mantida a preocupação de ultrapassar a dimensão individual dos relatos para encontrar neles o coletivo ${ }^{(15)}$.

\section{Análise dos Dados}

Após a transcrição das entrevistas com os acompanhantes, para o tratamento dos dados foi utilizada a análise de conteúdo temática que "consiste em descobrir os 'núcleos de sentido' que compõem a comunicação, e cuja presença ou freqüência de aparição pode significar alguma coisa para o objetivo analitico escolbido"(16). Nesse procedimento analítico, identificam-se os "núcleos de sentido", unidades de significação no conjunto de uma comunicação.

\section{RESULTADOS}

No presente estudo, participaram 12 acompanhantes. Analisando as características sociais destes sujeitos observou-se que os mesmos tinham média de idade de 37,5 anos. Por norma da instituição estudada, não são permitidos acompanhantes menores de 18 anos.

Quanto à escolaridade, 41,7\% (5) dos entrevistados cursaram o ensino médio completo e 33,3\% (4) possuíam ensino fundamental completo. O ensino fundamental incompleto foi cursado por $16,7 \%$ (2) dos entrevistados e um $(8,3 \%)$ (1) era analfabeto.

Analisando os acompanhantes com relação ao sexo, verificamos que a maioria era do sexo feminino, 75\% (9) e $25 \%$ (3) eram do sexo masculino.

Considerando o vínculo entre acompanhantes e parturientes, observamos que são pessoas próximas sendo que $58,3 \%$ (7) eram as mães, $25 \%$ (3) eram os companheiros e igual percentual de 8,3\% (1) para irmã e comadre, respectivamente.

$\mathrm{Na}$ Instituição em que o presente estudo foi realizado, a presença do acompanhante é tida como norma e é incentivada. São oferecidos cursos regulares de orientação às gestantes e seus acompanhantes. Entretanto, chamanos a atenção o fato de que 83,3\% (10) dos acompanhantes não terem participado do curso oferecido pela instituição. Apenas 16,7\% (2) receberam orientação no pré-natal.

Depreendemos das falas dos sujeitos do estudo três categorias temáticas centrais: a postura e prática dos acompanhantes no processo de parturição; o domínio do "fazer" pelo profissional de saúde no contexto institucionalizado de assistência ao parto e reconhecendo a condição do acompanhante.

Sobre a primeira categoria temática central, a postura e prática dos acompanhantes no processo de parturição, identificamos como núcleos de sentido: "dar força", "ficar junto/ao lado" e "observar tudo".

O suporte provido pelo acompanhante à parturiente contempla, na prática, os aspectos emocionais (encorajar, tranqüilizar, incentivar).

"Ab! É importante eu vim ficar do lado, né. Porque dá uma força pra pessoa". (A4, mãe)

"Pedi pra ela ter calma porque tudo ia dar certo. Ab!, sei, lá, eu apoiava muito ela, pedia pra ficar mais calma que ia correr tudo bem”. (A9, companheiro)

Este momento de apoio é marcado pela transmissão de informações sobre o processo, de valores morais e de comportamento. As mulheres acompanhantes tomam as experiências vividas em seus corpos para conduzirem o apoio à parturiente, evidenciando certa postura socializatória e imperativa, evocando os atributos maternos (resignação, sofrimento e recompensas). 
"Eu dizia que a tendência das dores era piorar mesmo. Mas que assim que nascesse... viria a recompensa". (A13, mãe)

"Eu fiquei ali junto dela dando uma força... Toda ver que ela sentia dor en pedia pra ela manter a calma, que ela tinha que pensar no nenê, que ela tinha que ajudar a fazer força”. (A3, mãe)

Depreendemos ainda que participar como acompanhante reveste-se de uma postura fiscalizadora do serviço prestado pelo serviço de saúde.

"Ah! Eu fiquei olhando né! Observando tudo, porque en sou muito curiosa. Eu fiquei olhando... Eu perguntava tudo o que via de diferente...". (A1, comadre)

"O que eu fiz... olhando o sistema como é que eles estavam atendendo". (A2, companheiro)

O compartilhar as experiências com a parturiente é permeado por curiosidade e, ao mesmo tempo por controle, o que pode se constituir de um importante fator de recusa dos profissionais de saúde em assistir à parturiente na presença do acompanhante. Alguns sujeitos do estudo mencionaram que foram convidados pelo médico a se retirar, sob a justificativa de que um dado procedimento seria realizado.

No espaço institucionalizado, as mulheres entregamse com simplicidade e confiança às normas e rotinas do serviço, submetendo-se a regras do saber científico e tecnológico. Neste espaço, o domínio médico (seu saberpoder) é percebido pelos acompanhantes, como um espaço em que sua posição lhes parece desviante, como evidenciado na segunda categoria temática central, o domínio do "fazer" pelo profissional de saúde no contexto institucionalizado de assistência ao parto. Nesta categoria identificamos os seguintes núcleos de sentido: "quem faz é o médico" reduzindo a participação do acompanhante no processo de parturição em "dar espaço para eles fazerem o trabalho deles".

'Porque eu sei que só quem faz é o médico. Eu não posso fazer nada, não posso pegar em nada que... as infecções que dá, então os médicos têm mais prática. Mas se ele pedisse eu ajudava...". (A1, comadre)

Numa situação de dependência, os acompanhantes relativizam suas ações a mercê de condições em que seja permitido atuarem, de modo a não atrapalhar a equipe médica e de saúde na execução do seu trabalho.

"...sempre na hora que eles faziam algum atendimento, fazia alguma coisa en ficava longe, meio destacado pra não atrapalhar eles, né!" (A2, companheiro)

"Eu fiz massagem na barriga dela, conversei com ela pra ela ficar calma, falava para ela ajudar os médicos, não atrapalhar, faz̧er força mesmo”. (A7, mãe)
Neste sentido, o médico é a figura central, administrando os procedimentos e o tempo na condução do processo de parturição, cabendo à parturiente ser paciente e colaborativa e, ao acompanhante, ajudá-la a manter-se nesta disposição.

Os acompanhantes evidenciam elementos centrais que configuram a sua relação desigual com o profissional de saúde, por ser este dotado de saber e poder, percebendose aos olhos do outro (profissional) em segundo plano na atenção, ao mesmo tempo em que se consideram satisfeitos, por estes responderem seus questionamentos com educação.

"Acho que eles até ignoram a gente. O importante é a paciente". (A5, mãe)

"Ele explicava direitinho, não era assim bruto". (A1, comadre)

A receptividade do profissional de saúde para com a parturiente e seus familiares se reveste de valor e satisfação, considerando os momentos de inseguranças e dúvidas que envolvem o parto.

Reportando-nos a terceira e última categoria temática central, reconhecendo a condição do acompanhante, os acompanhantes se percebem: "sem coragem", "sem atitude", "sem saber o que fazer".

"eu estava meio ansioso e não conseguia tomar atitude nenhuma"(A9, companheiro)

"Eu não tive coragem de ajudar... Eu estava, como se diz... com as mãos atadas... Não tinha experiência nenhuma para ajudar ela”(A10, companheiro)

Considerando que a maioria dos acompanhantes não participou do curso oferecido pela instituição ou de qualquer outro curso relacionado ao tema em questão, justifica-se a condição figurativa dos acompanhantes. Atrelado a isto, há uma dissociação entre o que se preconiza por cuidado humanizado e a prática no contexto institucional hospitalar, onde predomina o modelo normatizado e tecnicista do cuidado, sustentado no risco potencial à saúde materna e da criança.

\section{DISCUSSÃO}

A análise do perfil dos acompanhantes, sujeitos deste estudo, evidencia a condição de origem do evento parto como essencialmente feminino. A esse respeito, é necessário lembrar que historicamente a gravidez, o parto e a maternidade foram considerados como atributos de exclusividade do mundo feminino, não sendo permitida a participação dos homens, a não ser como procriadores, provedores e possuidores de uma descendência ${ }^{(16)}$. Isso se deve em parte a existência de uma convenção social 
em que em situações como o nascimento e parto o esperado é que se escolha alguém da família para participar, como evidenciado neste estudo.

Em uma pesquisa etnográfica sobre o perfil de acompanhantes de parturientes, também se observou a tendência de uma maior participação feminina (64\%) em uma amostra de 525 acompanhantes ${ }^{(17)}$. Vale destacar que a participação masculina nos processos da maternidade vem se tornando mais expressiva na atualidade nos diferentes contextos, mostrando um indício de transformação na construção de gênero e família ${ }^{(11)}$.

O significado da participação como acompanhante se ancora no apoio emocional. Tem sua maior expressão por transmitir a parturiente maior segurança e conforto, em um momento em que a solidão e o medo se fazem presentes. Ser deixada sozinha durante o trabalho de parto representa uma ameaça à mulher ${ }^{(18)}$.

Dentre as atividades de suporte que o acompanhante pode prover à parturiente, encontram-se de atividades de apoio emocional, aquelas de conforto físico como auxiliar no banho e na deambulação, e encorajar no período expulsivo ${ }^{(19)}$. Estudos verificaram uma elevada satisfação das mulheres com a experiência do parto, quanto ao fato de terem recebido suporte emocional seja por doulas $^{(20)}$ ou por familiares ${ }^{(21)}$.

A dor de parir é uma manifestação esperada pelas mulheres. A percepção da sensação de dor faz parte de um aprendizado que diz respeito a significados socialmente compartilhados. Particularmente a dor de parto é valorizada como uma dor que tem recompensa, como observado na fala das acompanhantes. Tal concepção advém de construções sociais e culturais sobre maternidade ${ }^{(22)}$, construída sob as bases da abnegação e sacrifício.

Num contexto atual em que a qualidade da assistência à saúde tem sido palco de constantes críticas por deficiências ligadas a fatores diversos, a participação do acompanhante ganha importância de agente fiscalizador. Particularmente, na assistência obstétrica, as medidas intervencionistas têm resultado em iatrogenias, suscitando um alerta geral de controle e fiscalização dos serviços de saúde.

A curiosidade e controle manifesto em atitudes e ações dos acompanhantes têm reflexos na forma como os profissionais os percebem. Estudo realizado em 2004(9) através de observações e entrevistas com 24 profissionais (médico obstetra, neonatologista, enfermeira e auxiliar de enfermagem) sobre suas experiências com acompanhantes no parto, identificou que os profissionais têm crenças e valores negativos em relação aos acompanhantes pela possibilidade dos mesmos interferirem em suas ações e questionarem suas condutas.

A institucionalização do parto no século XX incorporou diversos avanços tecnológicos, ao mesmo tempo em que o processo de parturição passou a ser de apropriação e legitimação de um saber pelo profissional de saúde.

Neste sentido, a participação do acompanhante mostra-se limitada pelas bases do saber técnico e científico, as mesmas bases que posicionaram os médicos como detentores legítimos das práticas terapêuticas e da assistência à saúde. A estrutura lógica deste saber determina como cada envolvido deve se comportar. O domínio médico se legitima também entre os membros da família da parturiente, cuja participação se faz sob autorização da instituição médica ${ }^{(23)}$.

No espaço institucional, evidenciam as propriedades atuantes dos agentes, profissionais de saúde, parturiente e acompanhante mostram-se presentes na medida em que, "são tidas em consideração como princípio de construção do espaço social"(24).

O domínio médico se expressa em um contexto de parturição em que a noção de risco mostra-se presente. A tecnologia médica apresenta-se como resposta ao controle desse risco. Esta lógica, levada ao extremo, passa a justificar a utilização incondicional de intervenções na condução do trabalho de parto e parto. Tal condição reforça o saber-poder médico em detrimento de qualquer participação ativa da mulher e do acompanhante no processo de parturição, restringindo-se ao papel de "não atrapalhar".

Neste campo de forças em que operam as relações entre profissional de saúde, parturiente e acompanhante, de forma singular, os acompanhantes expressam a imagem que têm dos profissionais, no espaço institucionalizado da assistência ao parto. Neste espaço organizacional, o fazer fica reservado para quem é dotado de saber, o médico.

Apesar dos serviços incorporarem como norma institucional a participação do acompanhante no processo da parturição, estamos muito aquém de cumprir com os preceitos da humanização. A vigência de um modelo tecnocrático, incorporado profundamente às práticas, é um grande obstáculo para a humanização.

A assistência à mulher, em especial ao parto, tem se tornado um ato técnico e impessoal, não abrindo espaço para que se estabeleça uma interação. Vale considerar que relação humana é um fenômeno decisivo para determinar a dimensão do processo de acolhimento e sintonia entre as pessoas para efetivação do cuidado ${ }^{(25)}$.

Assim, depreendemos que a incorporação de medidas ou estratégias voltadas para a humanização, como a participação do acompanhante no processo de parturição, tem se conformado como ação isolada do contexto institucional, ou seja, o discurso da humanização não encontra espaço real para se expressar em ações. A este respeito, tem se observado que nos serviços de saúde, há uma constante tensão entre a mudança e a permanência de dois paradigmas opostos: da humanização e o tecnocrático ${ }^{(2)}$. 
Analisando a última categoria temática, a insatisfação dos acompanhantes quanto à maneira com que participam do processo de parturição pode ser evidenciada como "sem coragem", "sem atitude", "sem saber o que fazer", entretanto, o acompanhante deve ser visto como alguém que está vivenciando um momento especial, logo ele também precisa ser acolhido pela equipe de saúde, o que poderá contribuir para que se sinta confiante e reconhecido no seu papel, refletindo na sua participação como suporte à parturiente ${ }^{(1)}$.

\section{CONCLUSÃO}

Os resultados deste estudo possibilitaram perceber a produção de significados auto e hetero-referidos a um conjunto pertinente de relações sociais e elementos institucionais, através das falas dos acompanhantes de mulheres no espaço institucionalizado de assistência ao parto.

A presença do acompanhante durante a assistência ao trabalho de parto e parto é uma das práticas reconhecidas como benéficas pela OMS para atenção de partos de baixo risco, entretanto, tais benefícios estão na dependência de fatores tais como: as características assistenciais dos hospitais, do tipo de provedor do suporte e da duração do suporte.

Tendo por base os achados deste estudo sobre a constituição subjetiva do espaço e ação dos acompanhantes, podemos considerar que a participação limitada do acompanhante é decorrente do modelo de atenção intervencionista ao parto, dos preconceitos e descrédito frente aos benefícios que tal prática pode proporcionar, incorrendo na falta de compromisso dos profissionais de saúde em preparar e inserir o acompanhante no processo.

Consideramos importante a implementação de estratégias mais efetivas no que tange a sensibilização dos profissionais de saúde, para a aceitação e integração do acompanhante no processo de parturição, bem como de construir o espaço do acompanhante num contexto institucional de saúde. Frente a esta situação, os cursos de orientação no pré-natal tornam-se fundamentais para que o acompanhante sinta-se preparado emocionalmente e tenha clareza de como poderá ajudar no processo.

A sociabilidade é um pré-requisito ao bom atendimento, na medida em que ela permite a abertura aos outros e ao mundo exterior. O profissional de saúde não é apenas valorizado pela habilidade técnica, pela pronta resolutividade, mas também pelo seu lado humano. Desta forma o acompanhante se sentirá acolhido como alguém que veio ajudar e não atrapalhar.

\section{REFERÊNCIAS}

1. Brüggemann OM, Parpinelli MA, Osis MJD. Evidências sobre o suporte durante o trabalho de parto/parto: uma revisão da lieratura. Cad Saúde Pública = Rep Public Health. 2005; 21(5): 1316-27.

2. Diniz CSG. Entre a técnica e os direitos humanos: possibilidades e limites da humanização da assistência ao parto [tese]. São Paulo: Faculdade de Medicina da Universidade de São Paulo; 2001.

3. Organização Mundial de Saúde. Tecnologia apropriada para nascimento e parto. Traduzido por Hotminsky SN. Rev. Venâncio SI. 1985.p.436-7.

4. World Health Organization. Care in normal birth: a practical guide. Maternal and Newborn Health - Safe Motherhood Unit. Geneva: WHO; 1996.

5. Brasil. Ministério da Saúde. Portaria n. 569, de 1 de junho de 2000. Dispõe sobre a criação do Programa de Humanização ao Pré-natal e nascimento no âmbito do Sistema Único de Saúde. Diário Oficial da União, Brasília (DF); 2000 Jun 8; Seção 1:4.

6. Lieberman AB. Easing labor pain: the complete guide to a more comfortable and rewarding birth. Boston: Harvard Common Press; 1992.

7. Zhang J, Bernasko JW, Leybovich E, Fahs M, Hatch MG. Continuous labor support from labor attendant for primiparous women: a meta-analysis. Obstet Gynecol. 1996; 88(4 Pt 2):739-44.

8. Hodnett ED. Caregiver support for women during childbirth (Cochrane review). In: The Cochrane Livrary. Oxford: Update Software; 2002.

9. Pinto CMS, Hoga LAK. Implantación del proyecto de inserción del acompañante en el parto: experiencias de los profesionales. Cienc Enferm. 2004; 10(1): 57-66.

10. Ratto KMN. É possível humanizar a assistência ao parto? Avaliação de dois anos da Maternidade Leila Diniz. Saúde Foco. 2001; 21: 115-35.

11. Florentino LC. A participação do acompanhante no processo de nascimento na perspectiva de humanização [tese]. São Paulo: Escola de Enfermagem da Universidade de São Paulo; 2003.

12. Rede Nacional Feminista de Saúde, Direitos Sexuais e Reprodutivos. Dossiê de humanização do parto. São Paulo: Rede Nacional Feminista de Saúde, Direitos Sexuais e Reprodutivos; 2002.

13. Brasil. Lei n.11.108. Altera a Lei n.8.080, de 19 de setembro de 1990, para garantir às parturientes o direito à presença de acompanhante durante o trabalho de parto, parto e pósparto imediato, no âmbito do Sistema Único de SaúdeSUS. Diário Oficial da União, Brasília (DF); 2005 Abr 8.

14. Minayo MCS. O desafio do conhecimento: pesquisa qualitativa em saúde. 4a ed. São Paulo: Hucitec-Abrasco; 1996.

15. 15 Rigotto RM. As técnicas de relato orais e estudos das representações sociais em saúde. Ciênc Saúde Coletiva. 1998; 3(1):116-30.

16. Jones RH. Pai e paternidade [texto na Internet]. 2005 [citado 2005 Dez 20]. Disponível em: http://www.amigasdoparto. com.br/ac007.html

17. Hotimsky SN, Alvarenga AT. A definição do acompanhante no parto: uma questão ideológica? Rev Estud Fem. 2002; 10: 461-81.

18. Klaus MH, Kennell JH. Pais / bebê: a formação do apego. Porto Alegre: Artes Médicas; 1993.

19. Pinto CMS, Basile ALO, Silva SF, Hoga LAK. O 
acompanhante no parto: atividades desenvolvidas e avaliação da experiência. REME Rev Min Enferm. 2003; 7(1):41-7.

20. Leão MRC, Bastos MAR. Doulas apoiando mulheres durante o trabalho de parto: experiência do Hospital Sofia Feldman. Rev Latinoam Enfermagem. 2001; 9(3):90-4.

21. Santos OM, Siebert ER. The humanization of birth experience at the University of Santa Catarina maternity hospital. Int J Gynaecol Obstet. 2001; 75 Suppl 1: S73-9.

22. Helman CG. Cultura, saúde e doença. 2a ed. Porto Alegre:
Artes Médicas; 1994.

23. Scavone L. Impactos das tecnologias médicas na família. In: Scavone L. Dar a vida e cuidar da vida: feminismo e ciências sociais. São Paulo: Editora UNESP; 2004. p. 89-99.

24. Bourdieu P. O poder simbólico. 4a ed. Rio de Janeiro: Bertrand Brasil; 2001.

25. Caron OAF. Parturiente e equipe obstétrica: a difícil arte da comunicação [tese]. São Paulo: Escola de Enfermagem da Universidade de São Paulo; 1998. 